Trinity University

Digital Commons @ Trinity

Communication Faculty Research

Communication Department

$5-2020$

\title{
Blurring Boundaries: Exploring Tweets as a Legitimate Journalism Artifact
}

Zhaoxi Liu

Trinity University, zliu@trinity.edu

D. Berkowitz

Follow this and additional works at: https://digitalcommons.trinity.edu/comm_faculty

Part of the Communication Commons

\section{Repository Citation}

Liu, Z., \& Berkowitz, D. (2020). Blurring boundaries: Exploring tweets as a legitimate journalism artifact. Journalism, 21(5), 652-669. http://doi.org/10.1177/1464884918775073

This Post-Print is brought to you for free and open access by the Communication Department at Digital Commons @ Trinity. It has been accepted for inclusion in Communication Faculty Research by an authorized administrator of Digital Commons @ Trinity. For more information, please contact jcostanz@trinity.edu. 


\title{
Blurring Boundaries: Exploring Twitter as a Legitimate Journalism Artifact
}

\author{
Zhaoxi "Josie" Liu \\ Trinity University \\ Dan Berkowitz \\ University of lowa
}

\begin{abstract}
This study explores journalists' use of Twitter and what it means for their craft. Based on eight weeks newsroom observation and more than a dozen in-depth interviews with reporters and editors at a big metro newspaper, the study found that journalists had contradicting views on whether or not to accept tweets, a form of snippet artifact, as a legitimate journalism artifact, leading to the blurring artifact boundary. Related, journalists faced uncertainties and ambiguities regarding the implications of such snippet artifact for the journalism craft and its core mission of informing the public.
\end{abstract}

\section{Keywords}

artifact boundary, boundary work, newsroom ethnography, social media, Twitter

\section{Introduction}

In the newsroom of a large metro daily newspaper, where the fieldwork was conducted, two veteran reporters were engaged in a brief but animated conversation one day. One reporter who covered the military asked the other, "Is Twitter journalism?" The government beat reporter responded, "It is journalism. It is information. People are getting their news on Twitter." To that 
the military reporter retorted, "If someone thinks they can get information in 140 characters, he is an idiot!" He added, "If all people want is something like tweets, that scares the bejesus out of me." Before leaving the conversation, the military reporter announced, "it is noon time. It is good time to tweet my story. Tweeting is a way to say: hey, I have a story!”

The above exchange teases out some key issues addressed by this study. First, the contradicting views among journalists regarding whether tweets can be viewed as a legitimate journalistic form; second, Twitter's implication for the craft of journalism. The purpose of this study is to explore whether journalists consider a tweet a legitimate artifact of journalism, raising a new kind of boundary question - the boundary of the artifact. In the Merriam-Webster Dictionary, artifact is defined as something characteristic of or resulting from a particular human institution, period, trend, or practice. For the purpose of this study, "artifact" refers to the material form characteristic or resulting from a particular practice, journalism. In the aforementioned conversation, the reporter asked "Is Twitter journalism," but he was actually referring to the tweets, as he emphasized on 140 characters. The artifact discussed throughout this article is the tweet, rather than Twitter the platform.

Furthermore, if people get into the habit of reading only snippets like tweets instead of the full story, will the journalism craft as we know it become obsolete? Can journalism still fulfill its fundamental mission of informing the public? Through an ethnographic newsroom study, this article asks these questions from the journalists' point of view. It goes beyond tweets to address the broader trend of a snippet culture and its implications for journalism.

In November 2017, Twitter doubled its character limit to 280. However, many people consider even 280 characters too short to be meaningful, even though the new limit is 
rarely reached (Tsukayama, 2017). Tweets are still snippets, and the concerns and issues raised by the journalists in this study are still relevant.

\section{Conceptual Framework}

Launched in 2006, Twitter now has 330 million monthly active users, according to the latest numbers released by the company (Twitter, 2018). In 2017, 11\% of American adults reported getting news from Twitter, according to a recent survey by Pew Research Center (Shearer and Gottfried, 2017). Plenty of research has been done on Twitter's impact on journalists and journalism. Some explored Twitter's role as a source of major breaking news (Kwak et al., 2010; Scoble, 2008), a reporting tool (Broersma and Graham, 2012; Dredge, 2014; Vis, 2013), or a distribution channel and marketing tool (Baughan, 2015; Lasorsa et al., 2012). Some examined in detail the content of journalists' tweets (Coddington, Molyneux and Lawrence, 2014; Lasorsa, Lewis and Holton, 2012; Lawrence et al., 2014; Papacharissi and Oliveira, 2011; Molyneux, 2015). Some looked into how Twitter changed the journalist-audience relationship to facilitate participatory journalism (de Zuniga, Diehl and Ardevol-Abreu, 2018). Still others have inquired about the representations of journalists' personal and professional identities on Twitter (Bossio, 2017). Not to mention, President Donald Trump's active use of Twitter has garnered tremendous attention from news organizations (see, for example, Kang, 2017; Keith, 2016; Shear, 2016).

Building upon the existing literature, the current study examines journalists' use of Twitter from yet another relatively new angle, that of artifact boundary. More importantly, this study transcends inquiry of Twitter to explore the broader trend of a snippet culture, which is more or less ushered by Twitter. The current study argues that the tweet can be regarded as a snippet artifact, and explores how working journalists interpret the significance of such a snippet artifact for their craft and its core mission of informing the public. "The primary purpose of 
journalism is to provide citizens with the information they need to be free and self-governing" (Kovach and Rosenstiel, 2007:12). Few studies have specifically addressed the issue of artifact boundary, and even fewer examined this issue in light of journalism's fundamental role in democracy. The current study thus contributes to the inquiry of journalism boundary work by addressing a newly emerging trend from a unique perspective.

This study draws upon two conceptual elements: journalism boundary work (see, for example, Carlson and Lewis, 2015) and examining journalism from a cultural point of view (see, for example, Author, YYYY; Hanitzsch, 2007). On the one hand, it examines the boundary shift that defines the artifact of journalism in today's digital environment. On the other hand, it seeks to understand how journalists make sense of such boundary changes.

\section{Artifact Boundaries}

There are many boundaries of journalism, all dealing with questions about what should be considered journalism, who should be considered a journalist, and where and how to draw the line of demarcation (Carlson, 2015a; Lewis, 2012; Ryfe, 2012; Singer, 2015; Zelizer, 2004). Essentially, the boundary question is one of legitimacy vis-à-vis the profession of journalism (Lewis, 2015). The fast evolvement of digital technology and digital platforms, including social media, blogging, and mobile devices, posed new challenges to the established boundaries of who are journalists and what is journalism; what and who should be included or excluded as part of the journalism profession. Academic inquiries of these issues formed a new frontier of studying journalistic boundary work (e.g., Deuze, 2005; Hermida, 2012; Singer, 2005), generating buzzwords such as "blurring boundaries" (Franklin, 2014) and "citizen journalism" (Jewitt, 2009). There have been studies examining how the internet and platforms like Twitter are changing the traditional journalistic culture from a top-down, individual-centered expert system, to an open sourced, participatory, knowledge sharing, interactive exchange between the 
journalists and the public. The boundary, in term of news practitioners, thus shifted. Journalists have become more or less in collaboration with the social media public in news production (Deuze, 2005; Franklin, 2014; Hermida, 2012; Vis, 2013). The boundary of news is also shifting, as Twitter has introduced information from official and unofficial sources into the realm of news (Hermida, 2010). The discussion about Twitter's impact on journalism is far from over, however. The current study continues this boundary study from a rather new and different angle, that of the artifact of journalism - the actual product produced by the craft, in an attempt to advance the inquiry on emerging issues concerning the use of technologies.

Carlson (2015a:10) proposes a matrix to encompass different types of journalistic boundary work. This matrix includes three areas of journalism around which boundary work occurs: participants (who are journalists), practice (what practices are journalistic) and professionalism (norms and values of legitimate journalism). Within the three areas, each has three types of boundary work: expansion (to include new participants, practices and norms), expulsion (to exclude or expel deviants), and protection of autonomy (to keep out nonjournalistic actor and defend journalists' ability to define good practices and maintain independence).

The current study extends Carlson's matrix to include the physical form, or the artifact, of journalism. As technology and devices evolve rapidly, the question of what qualifies as a journalism artifact looms large and deserves separate inquiries, precisely because the artifact of journalism can no longer be taken for granted. In other words, as stated by Lewis (2015), we can no longer "assume that nonhuman objects do not 'matter' in the course of boundary work-for there is good evidence that they do" (223). This is especially the case when newer technologies and devices demand or are biased toward certain form, or artifact, of news presentation. 
Tweets fit the smart phone screen very well. As an artifact, they have their own distinct characteristics. First, the 140-character limit (now 280 characters) forces the reporter to condense information and parse words into a basic idea. Second, tweets often include shorthand and acronyms not commonly seen in regular news stories. Third, tweets have their own special language, such as the @ symbol and hashtag (Papacharissi, 2012). Using the @ symbol is a way of getting the attention of specific parties, and the hashtag connects to a broader conversation.

Traditional news stories, which range from a few hundred to a few thousand words, or, in newspaper jargon, from a few inches to dozens of inches, are no longer the only, or even the main, material form of journalistic product. In an age of fast and dramatic changes of hardware, software and consumers, the question of the actual material form of the craft— the artifactbecomes prominent. If the signature artifact of the craft is in decline, where does the future of the craft hold? What does this all mean for journalism? The boundary shift in terms of artifact, therefore, deserves urgent attention. This study thus examines a different kind of boundary question: Is the tweet a legitimate artifact of news?

The concept of artifact is no stranger to journalism studies. Hanitzsch (2007) mentions three ways of studying culture: as ideas, practice and artifact. In addition, Thurman and Walters (2013) explore live blogs as "one of the few Web-native artefacts" (87). Hermida (2010) also states that tweets can be regarded as artifacts. He maintains that microblogs "are creating new forms of journalism, representing one of the ways in which the Internet is influencing journalism practices and, furthermore, changing how journalism itself is defined" (300). Although these studies provide strong conceptual support for studying tweets and similar content as artifacts, none of them specifically conceptualizes artifact as a boundary issue. 
In his proposal to advance research on journalism boundary work, Lewis (2015) calls for attention to "material objects in general and technology objects in particular, as they relate to journalism and its boundaries" (223, italics original). He calls this a "conceptual innovation" (219). Some attempts have been made in this direction, such as studies on algorithm's influence on journalism and use of news writing robots (Carlson, 2015c, 2017). The current study contributes to this emerging area of study, as it considers tweets technological objects and explores whether they qualify as journalism. By doing so, this study examines "tools, technologies, and 'things' that become enrolled in the work of determining boundaries" (Lewis, 2015: 223).

\section{Boundary Work as Cultural Practice}

Furthermore, the current study explores the issue of artifact boundary from a cultural point of view. Cultural inquiry can be distinguished from other modes of inquiry, such as sociological studies, through its focus on meaning. Carey (1992) and Geertz (1973) hold that the central task of a cultural inquiry is searching for meaning, rather than generalization of universal laws. Seen through the cultural prism, the world of news becomes "more than just reporters' professional code of actions or the social arrangements of reporters and editors," but rather "a complex and multidimensional lattice of meanings for all those involved in journalism" (Zelizer, 2004: 175). This study intends to gain some insight into this lattice of meanings from the perspective of artifact boundary, through exploring how journalists themselves have interpreted the meaning of the artifact boundary change.

As Carlson (2015b) points out, "ways of doing journalism are inseparable from ways of understanding journalism" (350). Adoption of new technologies often times involves not only changes in practice, but also interpretation of the meaning of such changes. For instance, use of digital technology and multimedia led to a redefinition of the meaning of journalists' work, from 
assembling a car to taking the readers on a ride (Robinson, 2007). In a mobile obsessed and social media saturated environment, journalism has become a fluid, on-going production process as opposed to producing just a finite print product (Robinson, 2011).

The current study addresses a rather new trend, namely, the snippet culture nurtured by digital platforms such as Twitter and Snapchat, where bite-size messages, either text or video, prevail. As the news industry embraces ever-multiplying digital platforms, there seems to be a surge of such a snippet culture, adapting to viewers' ever-shortening attention span. The New York Times, for example, in a new design of its mobile version, began using briefs and slices of information in an attempt to attract younger readers (Pompeo, 2015). Likewise, Vox.com started creating "snackable snaps" specifically for Snapchat in order to attract an audience between 18 and 24 (Mullin, 2015a). The release of the Apple Watch in April 2015 triggered another round of downsizing news to fit the shrinking screen in even smaller nuggets, such as the one-sentence story for the Apple Watch (Bell, 2015; Fitts, 2015). Such a snippet culture disrupts what Carlson (2015b) calls the metajournalistsic discourse about the meaning of journalism, which could be formed and transformed by actors inside and outside journalism. The current study seeks to understand how actors inside journalism (i.e. journalists) interpret the meaning of their craft in the wake of such a snippet culture.

Here, boundary work and cultural practice are closely connected, "as various actors continually make and remake boundaries of acceptable practices through their interpretive labor" (Carlson, 2015b: 360). Journalists seek to tighten the boundaries to protect their autonomy and authority in defining the meaning of their profession. In other words, legitimization is simultaneously boundary work and cultural process (Carlson, 2015b). By interpreting a particular artifact as a legitimate form of news, thus a legitimate journalism artifact, journalists 
(re)draw the artifact boundary. Therefore the issue of artifact boundary is also a matter of cultural interpretation, concerning the meaning of using snippet artifact such as tweets vis-a-vis the meaning of journalism.

As mentioned earlier, for American journalists, informing the public, thus serving democracy, is considered the essence of the meaning of journalism. The code of the American Society of Newspaper Editors states that the goal of journalism is "to serve the general welfare by informing the people" (Kovach and Rosenstiel, 2007:14). Also, "[n]ews is that part of communication that keeps us informed of the changing evens, issues, and characters in the world outside" (Kovach and Rosenstiel, 2007:15). However, as news platforms and artifacts multiply, American public finds it harder to stay informed. In a national survey of more than 19,000 U.S. adults aged 18 and older conducted by Gallup, $58 \%$ of the respondents say "it is harder rather than easier to be informed today due to the plethora of information and news sources available" (Gallup, 2018: 2). It is therefore essential to consider the informing mission when discussing what the snippet culture means for journalism.

The current study thus asks the following two research questions:

RQ1: Do journalists interpret tweets as a legitimate journalism artifact?

RQ2: In the journalists' view, what does the use of snippet artifacts such as tweets mean for the journalism craft and its core mission of informing the public?

\section{Method}

This study used what Zelizer calls "newsroom ethnography" (Zelizer, 2004), including participant observation and semi-structured interviews. Empirically grounded, ethnography provides detailed, nuanced analysis of journalistic practice, supplementing sweeping theories with concrete findings of what actually happens in journalists' daily work (Zelizer, 2004; Anderson, 2013). Ethnography makes the invisible visible, allowing access to the usually hidden, 
behind-the-scenes world of journalists (Cottle, 2007). Instead of inference and "speculative generalizations" (Anderson, 2013:169), ethnography is able to reveal insights that other methods might not provide. Cottle (2007) points out that digital technology has shifted news production from one single site, the newsroom, to multiple sites and different platforms. This study also collected data from multiple sites—inside and outside newsroom, journalists' Twitter accounts, newspaper website, and social media sites.

This study was conducted at a daily newspaper in a major metropolis in Southwest United States with a population of more than 1 million. The chain-owned newspaper was the city's only daily newspaper, with a daily paid circulation of about 100,000 and a Sunday combined print and online circulation of about 200,000. The newsroom employed more than 140 reporters and editors. The newspaper operated one website with free content and another site with paid content. The annual page-view total of the free website in 2015 was over 500 million.

The field research lasted eight weeks in June and July of 2014. During that time, the researcher observed reporters in the newsroom (mostly at the Metro Desk) and accompanied them to public meetings, crime scenes and other events. Particular attention was paid to reporters' use of Twitter during their work both in and outside the newsroom. Besides observations, semi-structured interviews were conducted with 18 reporters and editors concerning their use of Twitter. Among them were beat reporters and editors (education, local government, military, court and crime, transportation, etc.), breaking news reporters, reporter interns, website and social media editors, and the chief editor of the newspaper. Their age ranged from early 20 s to late 60 s, and they had worked at the newspaper anywhere from a couple of months (interns) to about three decades (seasoned reporters and editors). The interviewees were asked questions such as, “Are tweets Journalism?” or "Why do journalists tweet so much?" 
Interview questions were devised based on issues emerging from the field observation and informal chats with journalists.

Each interview lasted between 40 and 90 minutes and were audio recorded and transcribed. Aside from these sit-down, one-on-one interviews, there were also dozens of shorter, less formal conversations with journalists. Through observations and interviews, the research studied journalists' practices and their reflections of those practices (Atkinson and Coffey, 2003; DeWalt and DeWalt, 2001).

The data gathered though the fieldwork-fieldnotes, interview transcripts, and various texts, including tweets and news stories, were carefully reviewed to identify themes and patterns in journalists' use of Twitter and reflection of such use (Emerson et al., 1995), which is presented in the following section.

\section{Artifact Boundary and Its Meaning for Journalism}

In presenting findings of the current study, this section begins by briefly describing how journalists used Twitter and how such use had become part of their routines. The analysis then moves on to explore whether the journalists legitimize tweets as a journalism artifact and what such snippet artifact meant for them.

\section{Twitter in Newsroom Routines}

Newsroom routines began at this newspaper in the early morning, when breaking news reporters and the online editor arrived at their desks, turned on their computers, and checked their Twitter feeds. Some reporters also regularly checked the Twitter feeds from local television stations throughout the day to avoid missing anything important or just to gauge whether a story was worth covering. When sent to cover a story, a reporter usually would first tweet a couple of photos from the scene. Throughout the day, the reporter would tweet updates of a story. At around midnight, when the full story, to be printed in the next day's newspaper, appeared first on 
the newspaper's paid website, the reporter would usually tweet the link. Sometimes, a reporter would live tweet the entire event, such as a school board meeting, or a major sports event, with text, photos and videos.

When there was breaking news, the news routine was all about Twitter. On an early Wednesday morning, the entire city was rampaged by torrential rain and flash floods swamped the morning commute. In response, the paper's social media editor sent out an email from home at 7:30 a.m. asking the news staff to tweet about the weather using a hashtag. Reporters and editors soon started to tweet photos of the rain and flood. For example, one reporter tweeted, "Thought I could wait out the rain but I think the rain waited me out instead," with a photo taken from her car showing the heavy rain pouring down her windshield. She actually pulled over her car on her way to work and sent out the tweet.

It needs to be noted, however, that the actual use of Twitter varied from individual to individual. Breaking news reporters relied more on Twitter than did feature writers, and younger reporters more than their older colleagues. One young reporter said he used Twitter without even thinking too much about it. "Kinda like making coffee every morning," he said. "It's just something I do." Overall, Twitter had become an essential part of the newsroom routine, so much so that, instead of the reporter's phone number, the newspaper printed the reporter's email and Twitter handle at the bottom of stories.

\section{But Are Tweets Journalism?}

Despite the fact that Twitter had become an indispensable part of journalists' professional life at this newspaper, journalists still had not resolved the question of whether tweets — a snippet artifact — can actually be considered as journalism, which is essentially a matter of legitimizing tweets as a journalism artifact. Interestingly, interviews with journalists of different ages, beats and experience levels yielded no clear-cut answers. Among the 18 journalists interviewed, very 
few gave a definite "yes" or "no" answer. For most of them, the answer was yes and no. In fact, these journalists often contradicted themselves—one minute they stated that tweets are not journalism, but then went on to note how tweets could be journalism, or at least part of it. The following section presents the main reasons provided by the journalists for accepting or rejecting tweets as a legitimate journalism form.

One argument reporters made is that tweets provide information, and by providing information, tweets would be fulfilling journalism's mission of informing the public. "People were reading my tweets as the journalistic resource to them to understand what was happening in real time. So yeah, I think a tweet can be journalism.” A similar view was held by other journalists. One editor put it this way: "Journalism traditionally has been called the first rough draft of history. So tweeting is just the first rough draft of the first rough draft." A second argument made by reporters is that Twitter is timely, providing a sense of immediacy and real time update, an attribute of good journalism. "People want to know immediately what's going on," said the chief editor of the paper.

While agreeing that tweets could be journalism, journalists often attached some qualifying conditions. "Not all tweets are created equal," said the chief editor of the newspaper, suggesting that any individual could take a photo and tweet from a crime scene, but not all of what they produce would be considered journalism. What kind of tweets, then, can be legitimized as journalism? Three factors were mentioned by the journalists:

- The tweets should be crafted by professional journalists;

- The information provided should be verified and accurate; and

- The presentation of that information should be in an objective manner. 
For example, a city government reporter said his tweets were different from citizens who tweet a city council meeting, because he had credibility as a long-time reporter for the paper:

I see a lot of non-journalists' tweets about stuff that I write about, that often times has bad information, skewed information. I try very diligently to be fair and balanced in my tweets as I am in my story, and also as accurate.

Thus, by stressing conventional journalistic values such as accuracy and objectivity, journalists can claim legitimacy and authority as professionals, distinct from everybody else who also has a smart phone and can tweet anytime, anywhere. Consistent with studies from the early years of newsroom adoption of internet technologies (Deuze, 2005; Singer, 2005; Robinson, 2007), this study found that despite the ever growing power of digital technology, journalists perhaps will never be ready to relinquish their authority as the legitimate, credible news producer and storyteller, if not gatekeeper.

At the same time, not all the journalists agreed that meeting these criteria legitimized tweets as journalism. Instead, some journalists pointed out that as snippets, tweets lacked some of the key elements of traditional journalism, such as context, detail, narrative, and depth. Journalism is "not your opinion, or something you've seen or just done. It's something that takes time and research to dig out," argued the chief editor. This view resonated with some reporters, including an intern who said that tweets don't "give you a lot of depth. Journalism is about reporting in depth, and I think that's the most important thing to understand about Twitter." A reporter of more than 30 years of experience denied tweet as journalism. "Journalism is finding the story, finding all the central people to the story. Journalism is to get all the voices of the story. Two sentences? That's not journalism.”

The first research question asks if journalists interpret tweets as a legitimate journalism artifact. This study found mixed views among the journalists. They tended to view some aspects of the tweet, such as its timeliness and immediacy, as journalistic qualities and deemed tweets as 
legitimate journalistic work. Other aspects, however, such as its snippet nature, render it lacking in depth and context, causing some of the journalists to delegitimize tweets as a journalistic form. Therefore for the journalists in this study, tweets could sometimes be a legitimate journalism artifact, but not always. In addition, to be legitimized as journalism, tweets needed to meet the conventional journalistic values such as objectivity, accuracy and verification. These professional values allowed journalists to keep out non-journalistic informational actors and defended their authority to define legitimate journalistic practices, which is the boundary work of protecting journalists' autonomy (Carlson, 2015a).

With all three types of boundary work - expansion, expulsion and protection of autonomy (Carlson, 2015a) — existing simultaneously, the result was neither a definite shift nor an absolute maintenance of the artifact boundary, but blurring of the boundary (see Figure 1). What does the blurring boundary mean for journalism? The next section will address the question.

\section{Contradictions and Ambiguities}

Such blurring indicated uncertainty, ambiguity and contradiction, as journalists struggled to figure out what such a snippet culture really meant for their craft. In journalists' interpretation of the meaning of such a snippet culture, there emerged four pairs of contradictions: means vs ends, whole story vs snippets, attraction vs distraction, and low vs high production values.

\section{Means vs. End}

Are tweets a means to an end, or are they the end in themselves? The question of means vs end essentially concerned whether, in the journalists' views, the tweet is merely a tool to serve journalism or is it in itself a legitimate form of journalism. 
Concerning the means perspective, tweets were seen by many as a marketing tool to promote written stories, as journalists frequently tweeted the link to their stories. A reporter covering local government added:

Twitter is sort of like a gateway or a step towards that [full story]; it helps the reader know something that might be important, but they have to take the next step and go to the link or do something beyond that tweet.

"It's a means to an end," explained the chief editor of the newspaper. "Twitter in and out itself doesn't do us, as the news institution, any good in terms of monetizing what our reporters do." He encouraged his reporters to tweet in order to generate more traffic to the newspaper's website, hence more online advertisement income.

These journalists were not alone in using Twitter, or social media in general, as a marketing tool to promote their work. According to a survey of 1.5 million journalists, about $75 \%$ of those surveyed say they use Twitter to build up their own brand (Suleman, 2015). At The Guardian, Twitter has long been widely used as both a news gathering and marketing tool, expanding the reach of stories and getting readers more involved (Ahmad, 2010). However, reporters don't always tweet the link to their full stories (Canter, 2015).

As an end in itself, tweets were not just serving journalism - they were journalism. A court reporter who had earned a name for live tweeting trials said he could pack more information about a trial into his live tweets than could be included in the print version of the story. In that sense, tweets were an end product that satisfied the most avid followers of a trial. As the reporter put it, "If you're following closely enough, you learn more through my Twitter handle than through the newspaper article." 


\section{Whole Story vs. Snippet}

Tweets and full stories are two very different kinds of artifact. Tweets are snippets, bits and pieces of information, whereas traditional news articles weave together information into a form of storytelling.

Some journalists interviewed for this study were concerned with this snippet culture trend. For example, a reporter/editor/blogger claimed that Twitter is made for superficiality:

We are reducing the news to a tweet; we are just skimming the surface. It's good that we know right away, but it's bad that what we know could be just a tiny piece of the very big picture.

Her view was echoed by a young reporter intern: "Writing complete stories is the craft of what we should be doing. That's the full thing; it's not just two lines."

But not every journalist deemed the snippet a bad thing for journalism. A web editor, for instance, said she often told the interns: "Write me a lead like you were gonna tweet something," or "pitch a story as you were writing a tweet." To her, the tweet was an artifact of its own merit, forcing the writers to choose their words carefully in order to get the points across in a snippet.

Probed deeper, this trend of presenting news in snippets has profound implications for journalism as a craft, and may very well harbinger the demise of the conventional artifact produced by the craft—news articles. John Graydon Symes (2011), a freelance journalist in London, once bashed the live blog of The Guardian as a "mish-mash of baffling tweets, irrelevant musings from the Guardian's comments" (para. 5). Symes laments the fact that such non-structured aggregation of nuggets have replaced the "tried and tested way that's served journalism well for over 100 years" (para.3) - the inverted pyramid stories. He titled his article, "The Guardian Newsblog and the Death of Journalism."

The issue of artifact therefore has broader implications for the craft as a whole. In an extreme situation, where the snippet is all the audience want and actually consume, and they 
rarely click the link to read the whole story, will journalists in the near future spend more time tweeting and snapchatting, and less time writing stories? If so, there may be a rise of snippet journalism and decline of traditional journalism, and the journalism as we know it may

eventually fade away. As the chief editor of the newspaper explained, when people were satisfied to just know the superficial information as presented in tweets, and didn't dig into the deeper story or even imaging there was a broader story, "that does endanger journalism."

\section{Low vs. High Production Values}

The whole story vs. snippet debate leads to the contradiction regarding production value.

Even if tweets were a legitimate journalism artifact, some journalists say, they have lower production values than full stories. One reporter said of tweets, "It is low production value. A lot of it out there is just BS." A court reporter admitted that tweets were not always great journalism. "I could throw in [the tweets] stuff that I thought was good, but wasn't like this has to go in the story. I still only tweeted stuff that I thought was important; just that the threshold was a little lower." Reporters did not regard tweets as of high production value also because they thought tweeting something was easier than reporting and writing a full story. As stated by a reporter: "I think that's [tweeting] not super quality journalism necessary. It is not hard. It's basically who can move their thumbs the fastest."

In contrast, the product that had the highest production value, these journalists said, was the print newspaper, which they still held as the benchmark of high quality journalism. "The articles that go into the newspaper are usually the best piece of journalism we do, and social media rarely have an impact on that," said an education reporter. His editor, who accepted tweets as journalism, pointed out, "but there are layers of quality, and hopefully this is still the gold standard," waving a stack of newspaper in his hand. 
Consequently, on the priority list of a lot of journalists, tweeting was ranked behind writing stories. "You can waste a lot of time tweeting to a basically limited audience, when your real work and worth is when you can produce a deeper, more nuanced story than what you can get in 140 characters," said the chief editor of the paper. For a city council reporter, "There is an inverse relationship between the number of tweets I put out on a meeting and the importance of that meeting." A 28-year-old reporter said it was more important to "put together the most accurate, the most comprehensive story" than to "obsessively tweet this whole meeting." She added, “I'm sorry I didn't tweet enough, but do you see my story versus the story on the local TV station? Whose is better?"

Despite the perceived low production value of tweets, journalists found themselves having to produce content with both low and high production values, having to learn to multitask while prioritizing. Reporters acknowledged that having to tweet a lot added to their workload, but very few complained. Instead, they considered the extra work necessary for the newspaper to survive and keeping their jobs. One reporter, for example, said being able to operate through different channels and produce content at different levels made him a better journalist. "In the near future, I think people who don't do these things a lot, people who don't know how to use them or don't value them are gonna be gone."

Could tweets also have high production value? Possibly. One reporter said of another reporter's live tweets from a major trial "the most riveting journalism" she had ever seen. In other words, tweets can be become its own form of journalism, such as live reporting, and has its own unique value.

\section{Attraction vs. Distraction}

As already mentioned in the means vs. end section, many journalists saw tweeting as a way to attract the audience. "We want our reporters to draw followers, but we want the followers 
also to come to our website, and read the stories, and get the background and context for the events," said the chief editor of the newspaper. At the same time, some journalists realized the reality that many people simply did not click the link to read the full story. Even if people did click the links to go to the story, studies have shown that most online newspaper visitors are "flybys." They arrive perhaps through a link on a social networking site or sent in an email and don't spend much time on the webpage (Barthel, 2015).

When using electronic devices, "people are easily distracted" (Beccaria and De SaintExupery, 2013: 22). In a world of “attention economy” (Bell, 2015: para 5), people’s limited attention has been the most sought after commodity and the true scarce resource. Inescapably, the readers are at once attracted and distracted by Twitter or other digital media. Still, journalists keep tweeting their stories, keep feeding the appetite for snippets. Are they shooting their own foot by tweeting so much? Most journalists in this study did not think so. "If people don't know what they're missing, you can't entice them," said a young education reporter. His team member, another education reporter, agreed: "If they don't know where to find your amazing, long form journalism, then, your efforts are wasted."

Yet to be fully understood is the impact of such "flyby" news consumption on the health of democracy. "We assume that an intelligent and informed citizenry is critical to the ability to make wise choices at the ballot box and to engage in meaningful civic activity. Has the Internet revolution degraded this ability, enhanced this ability, or simply moved it from one platform (traditional media) to another (digital, 21st century technology)?" (Kamarck and Gabriele, 2015: 11)

Such a concern is echoed among the journalists in this study, including the seasoned reporter mentioned at the beginning of the article, who called people who thought they could be 
informed by snippets "idiots." A young reporter expressed concerns for a less informed society, "I'm really worried about the death of newspapers and what that means for our democracy. We can become a dumb society, we can be manipulated by our government, we can be manipulated by the people we elect, by corporation, if we don't count on journalism."

To answer the second research question of how journalists interpret the meaning of using snippet artifact for the journalism craft and its core mission, this study found four pairs of contradictions. Some journalists saw tweets as a means to an end, or a marketing tool to promote their stories and drive traffic to their newspaper's website. But some journalists tweeted for the sake of tweeting, and the tweets became a journalistic product in their own right. Journalists then wrestled with the difference between the snippet form of journalism and old-fashioned news story. They expressed concerns about the possible demise of the traditional artifact of news stories and inefficiency in the snippet's ability to inform the public, and yet, they could not afford not to tweet.

Eventually, a blurring artifact boundary goes hand in hand with a lot of ambiguities and contradictions in journalists' interpretation of its meaning. Journalists embraced tweets while resenting them; had high hopes and grave concerns for using tweets; were ambiguous about tweets' impact and yet could not do away with them. For the journalists, imposing the boundary turned out to be a complex interpretative process without definite answers, albeit with far reaching implications for their profession. The two research questions - artifact boundary and its meaning - are therefore closely connected, as illustrated in figure 1 below.

\begin{tabular}{|c|c|c|}
\hline Expansion & Expulsion & Protection of Autonomy \\
\hline Tweets are journalism: & $\begin{array}{c}\text { Tweets are } \text { not journalism: } \\
\text { timeliness and immediacy }\end{array}$ & $\begin{array}{c}\text { Tweets could be journalism: if } \\
\text { met journalistic values: } \\
\text { objectivity, accuracy, } \\
\text { context. } \\
\text { verification, etc. }\end{array}$ \\
\hline
\end{tabular}




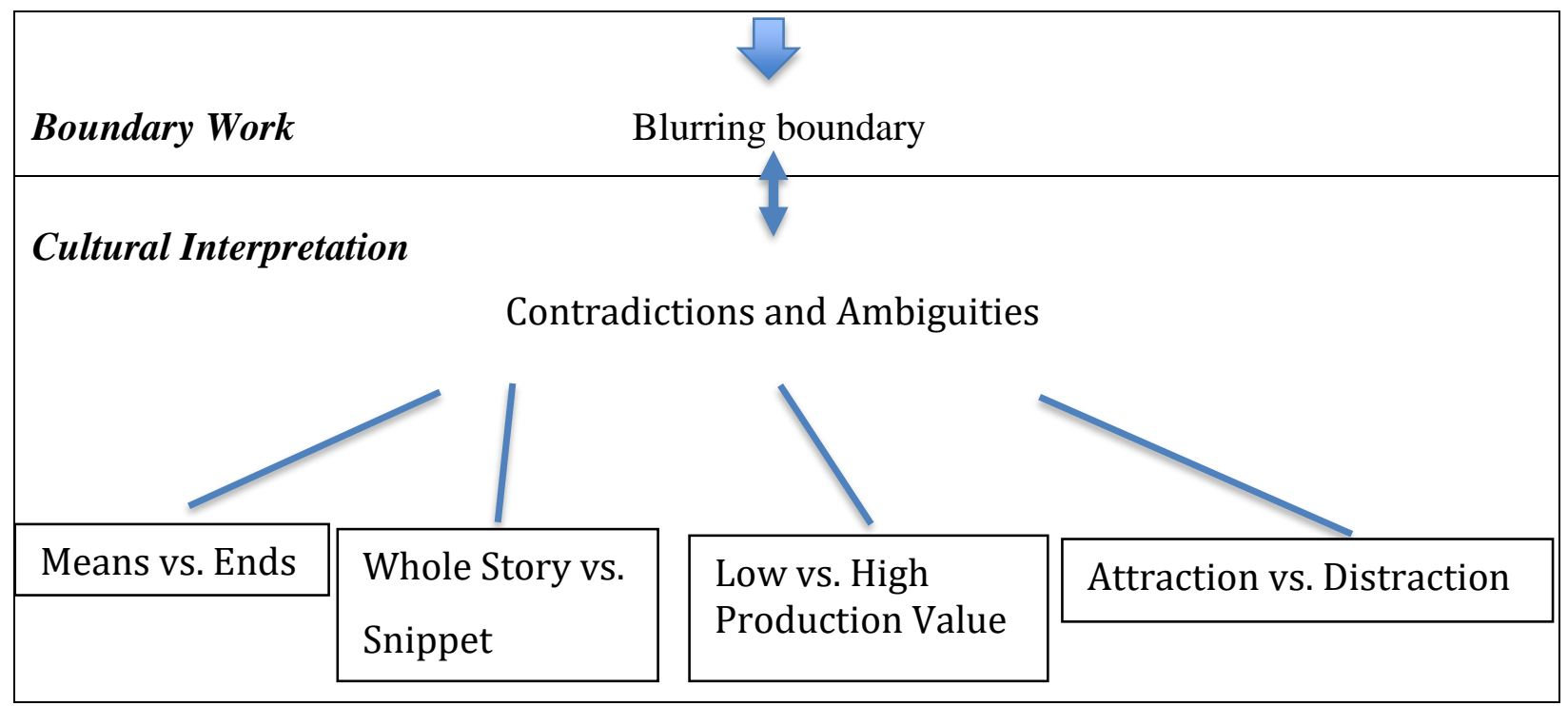

Figure 1

Journalists' Interpretive Process on Artifact Boundary and Its Meaning Regarding Tweets

\section{Conclusion}

Through an eight-week field research, the current study provides an in-depth inquiry into journalists' use of Twitter and what it means for their craft, foregrounding the issue of artifact boundary while exploring its deeper meaning from a cultural point of view. This study expands the boundary work of journalism to include the physical form of news and examines an emerging trend in journalism, namely, the increasing use of snippets. Furthermore, the study explores what the new turf of boundary work means for journalism and society through journalists' interpretations. The ethnographic study undertaken allowed the researchers to demonstrate in detail the nuanced interpretive process of these journalists, providing valuable insights that other methods might not provide.

The findings of the study demonstrate that boundary work regarding artifacts is unlikely to be clear-cut, as journalists simultaneously legitimized and delegitimized tweets as a journalism artifact. Unable to impose a clear-cut boundary, journalists faced uncertainties and ambiguities in interpreting what the prevalent use of snippets meant for their profession. Amid all the bewilderment, as shown in the study, journalists seemed to hold on to one essential 
meaning of journalism: its core mission to inform the public in order to maintain a healthy democracy. And yet, their ability to fulfill this mission is also called into question if the public is more often fed on superficial snippets than thoughtful, in-depth pieces of journalism.

The current study therefore calls for more sophisticated studies that drill further on people's news consumption habits. It is no longer sufficient to just know that people are getting their news on social media. Once they saw a posting on social media, do they actually click the link? Do they then read through the whole article? How often? On what topics? Etc., etc. These questions matter because they concern the viability of the craft of journalism as we know it, and the extent to which the public is truly informed.

The current study further argues that the boundary of journalism artifact has implications far beyond the format of news. Producing snippets and producing long pieces are two very different mode of production, and bear different result of informing the public and thus the overall health of democracy. The study on journalism artifact boundary and what it means for journalism, therefore, is an urgent and significant topic at a time of flourishing digital artifacts, and could be a fertile area of journalism studies in the near future. Although the study was conducted in 2014 and the journalistic use of tweets likely has changed somewhat since then, the questions addressed here are still relevant. They could also be asked about similar snippet artifacts, such as posts on Facebook or Snapchat, the push notifications on the home screen of mobile phones, and other forms of snippet that keep emerging.

It should also be noted that as many news organizations are busy producing short snippets to be distributed all over the internet, another, opposite, trend is emerging, that of producing long pieces. As the New Yorker has discovered, the stories that they had invested more effort attracted more readers, so their strategy to attract more audience is to publish more, better stories (Mullin, 
2015b). The central idea is to produce quality product that the readers are willing to pay for, rather than relying on advertisement revenue to support the production. Future studies could look into the viability of such an alternative business model and its impact on the future of journalism. 


\section{References}

Anderson CW (2013) Rebuilding The News: Metropolitan Journalism In The Digital Age.

Philadelphia: Temple University Press.

Author (YYYY)

Ahmad AN (2010) Is twitter a useful tool for journalists? Journal of Media Practice, 11(2): 145155.

Atkinson P and Coffey A (2003) Revisiting the relationship between participant observation and interviewing. In: Holstein JA and Gubrium JF (eds) Inside Interviewing: New Lenses, New Concerns. Thousand Oaks, CA: Sage, pp. 415-428.

Barthel M (2015) Newspaper: Fact sheet. Available at: http://www.journalism.org/2015/04/29/newspapers-fact-sheet/ (accessed 19 December 2015)

Baughan N (2015) Do Facebook, Twitter and Google offer news publishers salvation? The Guardian, 15 September, 2015. Available at: https://www.theguardian.com/medianetwork/2015/sep/15/facebook-twitter-google-apple-news-publishers-instant-articles (accessed 18 December 2015)

Beccaria L and De Saint-Exupery P (2013). Content and discontent. Harper's Magazine, October, pp. 21-25.

Bell E (2015) Apple watch highlights need for shorter news as screen sizes shrink. The Guardian, 26 April, 2015. Available at: http://www.theguardian.com/media/mediablog/2015/apr/26/apple-watch-shrinking-news-apps (accessed 28 April 2015)

Bossio D (2017) From "selfies" to breaking news: How journalists negotiate personal and professional identity on social media. Journalism Practice, 11(5), 527-543.

Broersma M and Graham T (2012) Social media as beat: Tweets as a news source during the 2010 British and Dutch elections. Journalism Practice, 6(3): 403-419.

Carey J W (1992) Communication As Culture: Essays On Media And Society. New York: Routledge.

Carlson M (2015a) Introduction: The many boundaries of journalism. In: Carlson M and Lewis SC (eds) Boundaries Of Journalism: Professionalism, Practices, And Participation. New York: Routledge, pp. 8-22.

Carlson M (2015b) Metajournalistic discourse and the meanings of journalism: Definitional control, boundary work, and legitimation. Communication Theory, 26(4), 349-368.

Carlson M (2015c) The robotic reporter: Automated journalism and the redefinition of labor, compositional forms, and journalistic authority. Digital Journalism, 3(3), 416-431.

Carlson M (2017) Automating judgment? Algorithmic judgment, news knowledge, and journalistic professionalism. New Media \& Society. https://doi.org/10.1177/1461444817706684

Carlson M and Lewis SC (eds) (2015) Boundaries Of Journalism: Professionalism, Practices And Participation. New York: Routledge.

Canter L (2015) Personalised tweeting: The emerging practices of journalists on twitter. Digital Journalism, 3(6), 888-907.

Coddington M, Molyneux L and Lawrence RG (2014) Fact checking the campaign: How political reporters use twitter to set the record straight (or not). The International Journal of Press/Politics, 19(4), 391-409. 
Cottle S (2007) Ethnography and news production: New(s) development in the field. Sociology Compass, 1(1), 1-16.

De Zuniga HG, Diehl T and Ardevol-Abreu A (2018) When citizens and journalists interact on twitter: Exceptions of journalists' performance on social media and perceptions of media bias. Journalism Studies, 19(2), 227-246.

Deuze M (2005) What is journalism: Professional identity and ideology of journalists reconsidered. Journalism Educator, 6(4): 442-464.

DeWalt KM and Dewalt BR (2001) Participant Observation: A Guide For Fieldworkers. Walnut Creek, CA: AltaMira Press.

Dredge S (2014) Social media, journalism and wars: 'Authenticity has replaced authority. The Guardian, 5 November, 2014. Available at: http://www.theguardian.com/technology/2014/nov/05/social-media-journalism-warsauthenticity (accessed 11 May 2015)

Emerson R, Fretz R and Shaw L (1995) Writing Ethnographic Fieldnotes. Chicago: The University of Chicago Press.

Fitts AS (2015) Why the New York Times apps look different. Columbia Journalism Review, May 11, 2015.

Franklin B (2014) The future of journalism. Digital Journalism, 2(3): 254-272.

Gallup (2018). American views: Trust, media and democracy. Available at:

https://knightfoundation.org/reports/american-views-trust-media-and-democracy (accessed

13 February 2018)

Geertz C (1973) The Interpretation Of Cultures: Selected Essays. New York: Basic Books.

Hanitzsch T (2007) Deconstructing journalism culture: Toward a universal theory. Communication Theory, 17(4): 367-385.

Hermida A (2010) Twittering the news: The emergence of ambient journalism. Journalism Practice, 4(3): 297-308.

Hermida A (2012) Tweets and truth: Journalism as a discipline of collaborative verification. Journalism Practice, 6(5-6): 659-668.

Jewitt R (2009) The trouble with twittering: Integrating social media into mainstream news. International Journal of Media and Cultural Politics, 5(3): 233-246.

Kamarck EC and Gabriele A (2015) The News Today: 7 Trends In Old And New Media. Washington, D.C.: Center for Effective Public Management at Brookings.

Kang C (2017) That old phone trump uses for twitter could be an opening to security threats. New York Times, 25 January, 2017. Available at: https://www.nytimes.com/2017/01/25/technology/donald-trump-phone-social-mediasecurity.html? r=0 (accessed 20 March 2017)

Keith T (2016) Commander-in-tweet: Trump's social media use and presidential media avoidance. NPR, 18 November, 2016. Available at: http://www.npr.org/2016/11/18/502306687/commander-in-tweet-trumps-social-mediause-and-presidential-media-avoidance (accessed 20 March 2017)

Kovach B and Rosenstiel T (2007) The Elements of Journalism: What Newspeople Should Know and the Public Should Expect. New York: Three Rivers Press.

Kwak H, Lee C, Park H, and Moon S (2010) What is twitter, a social network or a news media? WWW 2010, Proceedings of the 19th International Conference on World Wide Web, Raleigh, North Carolina, USA. pp. 591-600. 
Lasorsa DL, Lewis SC, and Holton AE (2012) Normalizing twitter: Journalism practice in an emerging communication space. Journalism Studies, 13(1): 19-36.

Lawrence RG, Molyneux L, Coddington M and Holton AE (2014) Tweeting conventions: Political journalists' use of twitter to cover the 2012 presidential campaign. Journalism Studies, 15(6), 789-806.

Lewis SC (2012) The tension between professional control and open participation: Journalism and its boundaries. Information, Communication and Society, 15(6): 836-866.

Lewis SC (2015) Epilogue: Studying the boundaries of journalism: Where do we go from here? In: Calrson M and Lewis SC (eds) Boundaries of journalism: Professionalism, practices and participation. New York: Routledge, pp. 218-228.

Molyneux L (2015) What journalists retweet: Opinion, humor, and brand development on twitter. Journalism: Theory, Practice and Criticism, 16(7), 920-935.

Mullin B (2015a) How vox.com plans to reach younger audiences with snapchat discover. Available at: http://www.poynter.org/2015/how-vox-com-plans-to-reach-youngeraudiences-with-snapchat-discover/386358/ (accessed 21 December 2015)

Mullin B (2015b) The talk of the web: How the New Yorker grew its digital audience by focusing on quality. Available at: http://www.poynter.org/2015/the-talk-of-the-web-howthe-new-yorker-grew-its-digital-audience-by-focusing-on-quality/386510/ (accessed 18 December 18 2015)

Papacharissi Z (2012) Without you, I'm nothing: Performances of the self on twitter.

International Journal of Communication, 6, 1989-2006.

Papacharissi Z and Oliveira MDF (2011) The rhythms of news storytelling on twitter: Coverage of the January 25th Egyptian uprising on twitter. Paper presented at the world association for public opinion research conference.

Pompeo J (2015) NYT now relaunching as free app on may 11. Available at: http://www.capitalnewyork.com/article/media/2015/04/8565980/nyt-now-relaunchingfree-app-may-11 (accessed 11 May 2015)

Robinson S (2007) Someone's gotta be in control here. Journalism Practice, 1(3): 305-321.

Robinson S (2011) "Journalism as process": The organizational implications of participatory online news. Journalism \& Communication Monographs, 13(3), 137-210.

Ryfe D (2012) Can journalism survive? Cambridge, UK: Polity.

Scoble R (2008) Twittering the earthquake in China. Available at: http://scobleizer.com/quakein-china/ (accessed 13 September 2016)

Shear MD (2016) Trump as cyberbully in chief? Twitter attach on union boss draws fire. New York Times, 8 December, 2016. Available at: https://www.nytimes.com/2016/12/08/us/politics/donald-trump-twitter-carrier-chuckjones.html?_r=0 (accessed 20 March 2017)

Shearer E and Gottfried J (2017) News use across social media platforms 2017. Available at: http://www.journalism.org/2017/09/07/news-use-across-social-media-platforms-2017/ (accessed 13 February 2018)

Singer JB (2005) The political j-blogger: 'Normalizing' a new media form to fit old norms and practices. Journalism: Theory, Practice \& Criticism, 6(2): 173-198.

Singer JB (2015) Out of bounds: Professional norms as boundary markers. In: Lewis SC and Carlson M (eds) Boundaries of journalism: Professionalism, practices, and participation. New York: Routledge, pp. 21-36. 
Suleman K (2015) Infographic: Journalists rely on twitter and PR sources. Available at: http://www.prweek.com/article/1354357/infographic-journalists-rely-twitter-pr-sources (accessed 17 September 2015)

Symes JG (2011) The Guardian newsblog and the death of journalism. In: Louse and Flea. Available at: https://louseandflea.wordpress.com/2011/02/22/the-guardian-newsblog-andthe-death-of-journalism/ (accessed 11 May 11 2015)

Takahashi B, Tandoc Jr EC and Carmichael C (2015) Communicating on twitter during a disaster: An analysis of tweets during typhoon Haiyan in the Philippines. Computers in Human Behavior, 50, 392-398.

Thurman N and Walters A (2013) Live blogging: Digital journalism's pivotal platform? Digital Journalism, 1(1): 82-101.

Tsukayama, H. (2017). Twitter is officially doubling the character limit to 280. Available at: https://www.washingtonpost.com/news/the-switch/wp/2017/11/07/twitter-is-officiallydoubling-the-character-limit-to-280/?utm term $=.850118070 \mathrm{ba3}$ (accessed 13 February 2018)

Twitter (2018). Q4 and fiscal year 2017 letter to shareholders. Available at: http://files.shareholder.com/downloads/AMDA2F526X/6019026941x0x970882/AF653BFB-8C4D-4D91-8F128867CDA665DB/Q4_2017_Shareholder_Letter.pdf (accessed 17 February 2018)

Vis F (2013) Twitter as a reporting tool for breaking news. Digital Journalism, 1(1): 27-47. Zelizer B (2004) Taking journalism seriously: News and the academy. Thousand Oaks, CA: Sage. 